\title{
Design of Bifunctional Antisense Oligonucleotides for Exon Inclusion
}

\author{
Haiyan Zhou
}

\begin{abstract}
Bifunctional antisense oligonucleotide $(\mathrm{AON})$ is a specially designed $\mathrm{AON}$ to regulate pre-messenger RNA (pre-mRNA) splicing of a target gene. It is composed of two domains. The antisense domain contains sequences complementary to the target gene. The tail domain includes RNA sequences that recruit RNA binding proteins which may act positively or negatively in pre-mRNA splicing. This approach can be designed as targeted oligonucleotide enhancers of splicing, named TOES, for exon inclusion; or as targeted oligonucleotide silencers of splicing, named TOSS, for exon skipping. Here, we provide detailed methods for the design of TOES for exon inclusion, using SMN2 exon 7 splicing as an example. A number of annealing sites and the tail sequences previously published are listed. We also present methodology of assessing the effects of TOES on exon inclusion in fibroblasts cultured from a SMA patient. The effects of TOES on SMN2 exon 7 splicing were validated at RNA level by PCR and quantitative real-time PCR, and at protein level by western blotting.
\end{abstract}

Key words Antisense oligonucleotide, Bifunctional antisense, Pre-mRNA splicing, TOES, Splice switching, Exon inclusion, Exon skipping

\section{Introduction}

Harnessing antisense oligonucleotides (AONs) to redirect the altered pre-messenger RNA (pre-mRNA) splicing and modulate target gene expression is an efficient therapeutic strategy for genetic disorders associated with alternative splicing. A number of AON approaches have been investigated on redirecting pre-mRNA splicing. The original strategy is to use AONs complementary to a cryptic splice site to prevent its use and favored selection of the authentic site [1]. This approach has been used regularly to alter the proportion of splice isoforms produced from mutated genes or alternative splicing units. In addition to blocking the splice sites, alternative splicing events are often controlled by regulatory proteins bound to exonic and intronic elements located beyond the alternative splice sites. A valid approach is to use AONs to directly 
target exonic or intronic elements by blocking the binding of regulatory proteins to these elements that are involved in premRNA splicing. This strategy has been successfully used to augment the exon 7 inclusion in SMN2 gene by using a short AON to target an intronic splicing silencer (ISS) within the gene [25]. Nusinersen, an 18-mer AON annealing to the ISS-NI element in SMN2 intron 7 is the first antisense drug approved by the US Food and Drug Administration (FDA) for treatment of any types of spinal muscular atrophy (SMA) [6-8]. This strategy has also been proved to be very effective in Duchene muscular dystrophy (DMD) by promoting the skipping of an exon in the $D M D$ gene to restore the interrupted reading frame hence partial rescue of the functional dystrophin protein $[9,10]$. Three AON drugs, eteplirsen for exon 51 skipping and golodirsen and viltolarsen for exon 53 skipping in the $D M D$ gene, have been approved by the FDA for treatment of DMD [11-13].

The other splice switching approach is the use of bifunctional oligonucleotides to increase the number of positively or negatively acting signals in an exon or intron and to regulate the alternative splicing. The oligonucleotides were designed with one domain (the antisense domain) annealing to the target exon or intron, and another domain (the tail domain) containing a sequence that either recruits RNA binding proteins involved in pre-mRNA splicing [14] or is made of a synthetic protein domain covalently linked to the antisense domain [15]. This approach may be designed as targeted oligonucleotide enhancers of splicing (TOES) for exon inclusion $[14,16]$, or as targeted oligonucleotide silencers of splicing (TOSS) for exon skipping [17].

The effectiveness of TOES as a potential therapy for SMA by augmenting exon 7 splicing in SMN2 gene has been approved both in vitro in cellular model $[14,16]$ and in vivo in mouse model $[18-$ 20]. A bifunctional oligonucleotide targeted to SMN2 exon 7 was expressed in transgenic mice within a modified U7 snRNA gene. Expression of the TOES-U7 RNA in a mouse model of SMA produced a substantial improvement in function and lifespan [20]. Two other bifunctional oligonucleotides targeting the intronic splicing silencers in $S M N 2$ intron 6 and intron 7, which have the dual effects of blocking the silencer and recruiting activator proteins, also showed the potential therapeutic effects in the transgenic mouse models of SMA [18, 19].

We describe here the details in design of bifunctional oligonucleotide for exon inclusion by correcting SMN2 exon 7 splicing as an example (Fig. 1). TOES oligonucleotides are designed to contain two domains, an antisense domain complementary to sequences of SMN2 gene and a tail domain comprising sequences known as binding moieties for splicing activator proteins. The following design principles for TOES oligonucleotides are followed: (1) the antisense sequence may anneal to the potential 


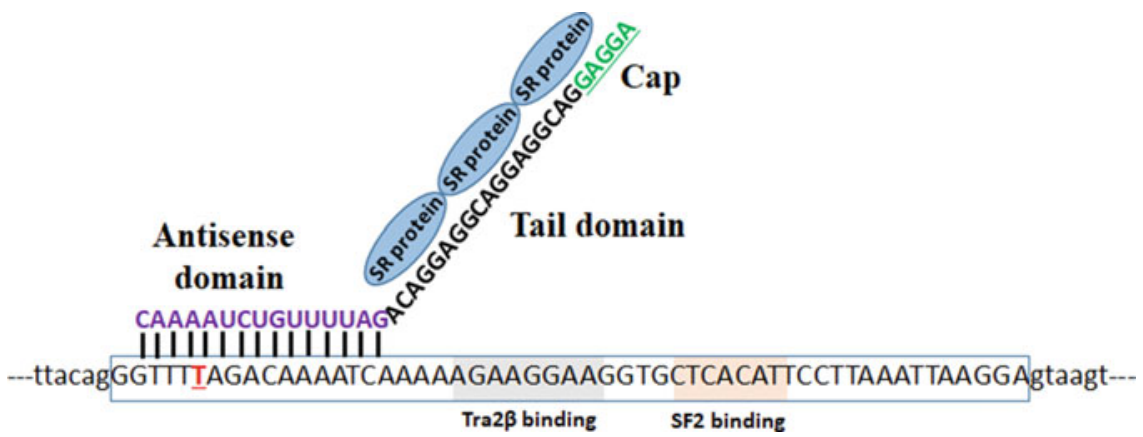

Fig. 1 Design of TOES to promote SMN2 exon 7 inclusion. The sequence of SMN2 exon 7 is in upper case and the flanking introns in lower case. Nucleotide 6 in SMN2 exon 7 is T (in red). Two shaded sequences are the binding sites of Tra2 $\beta$ and SF2/ASF, respectively. TOES is designed with two functional parts, the antisense domain to anneal to nucleotides 2-16 in SMN2 exon 7, the tail domain containing 3 repeats of "GGAGGAC" motifs to recruit the SR protein SRSF1. Cap contains five nucleotides at the $5^{\prime}$-end of the tail (in green, which is chemically modified)

splicing silencer binding sites in either intron 6, exon 7 or intron 7 , and should avoid any splicing enhancer binding sites; (2) a number of splicing enhancer motifs (e.g. SF2/ASF, SRSF1, and hTra2 $\beta 1)$ may be included in the tail domain to improve the effectiveness of the oligonucleotides; (3) chemical modification can be applied to the antisense sequence, but not to the tail domain, which may inactive protein binding to the tail domain. The effects on exon inclusion are evaluated at RNA and protein levels in fibroblasts cultured from a patient with type II SMA carrying three copies of SMN2 gene.

\section{Materials}

\subsection{AON Design}

2.2 Synthesis and Preparation of Bifunctional Oligonucleotides
1. Online software to identify splicing motifs, e.g., Human Splicing Finder (http://www.umd.be/HSF/HSF.shtml).

2. Online software to predict the secondary structures of the target gene and AONs (http://rna.urmc.rochester.edu/ RNAstructure.html).

3. Online software to calculate oligonucleotide properties on annealing temperature, GC content, and self-complementary (http://biotools.nubic.northwestern.edu/OligoCalc.html).

1. Oligonucleotides are synthesized commercially by Eurogentec Ltd. (www.eurogentec.com).

2. RNase and DNase-free distilled water ( see Note $\mathbf{1}$ ).

3. RNase and DNasefree $1.5 \mathrm{~mL}$ Eppendorf tubes. 
2.3 Culture of Skin Fibroblasts from SMA Patient

2.4 Fibroblast Transfection

2.5 RNA Extraction

2.6 cDNA Synthesis

2.7 Polymerase Chain Reaction (PCR)

2.8 Quantitative Real-Time PCR
1. Growth medium: Dulbecco's modified eagle medium (DMEM), 10\% Fetal Bovine Serum (FBS), 1\% Glutamax.

2. Trypsin-EDTA.

3. Phosphate-buffered saline (PBS).

4. Incubator set at $37^{\circ} \mathrm{C}$ and $5 \% \mathrm{CO}_{2}$.

1. Transfection reagent (e.g. Lipofectamine 2000).

2. Reduced serum medium for transfection (e.g. Opti-MEM).

3. 6 well plate or $35 \mathrm{~mm}$ diameter culture dish.

4. Sterile 1.5 mL Eppendorf tubes.

1. RNA isolation kit.

2. $\beta$-mercaptoethanol.

3. $70 \%$ ethanol (molecular grade).

4. RNase-free water.

5. $1.5 \mathrm{~mL}$ RNase-free Eppendorf tubes.

6. NanoDrop spectrophotometer.

1. cDNA synthesis kit.

2. Thermocycler.

3. $0.2 \mathrm{~mL}$ PCR tubes.

1. cDNA template from Subheading 2.6.

2. Taq Polymerase.

3. Primers ( $10 \mu \mathrm{M}$ forward primer and $10 \mu \mathrm{M}$ reverse primer). Primers sequences are shown in Table 1.

4. PCR buffer: $10 \times$ PCR buffer, $10 \mathrm{mM}$ dNTPs, $50 \mathrm{mM} \mathrm{MgCl}_{2}$, Taq DNA polymerase $(5 \mathrm{U} / \mu \mathrm{L})$, and nuclease-free water.

5. $0.2 \mathrm{~mL}$ PCR tubes.

6. Thermocycler.

7. Tris-Borate-EDTA $1 \times(\mathrm{TBE})$ buffer.

8. Agarose.

9. DNA gel stain.

10. Loading buffer.

11. DNA ladder.

12. Gel imaging system.

1. cDNA template from Subheading 2.6.

2. qPCR primers $(10 \mathrm{pmol} / \mu \mathrm{L}$ each $)$. Sequences are shown in Table 1 . 
Table 1

Sequences of primers used for exon 7 inclusion quantification by PCR and quantitative real-time PCR

\begin{tabular}{clll}
\hline Assay & Products & Sequences $\left(\mathbf{5}^{\prime}-\mathbf{3}^{\prime}\right)$ & $\begin{array}{l}\text { Annealing Tm } \\
\left({ }^{\mathbf{C}}\right)\end{array}$ \\
\hline PCR & $\begin{array}{c}\text { Full-length SMN2 } \\
(505 \text { bp })\end{array}$ & F: CTC CCA TAT GTC CAG ATT CTC TT & 55 \\
& $\Delta 7$ SMN2 $(451 \mathrm{bp})$ & R: CTA CAA CAC CCT TCT CAC AG & \\
qRT- & Full-length SMN2 & F: ATA CTG GCT ATT ATA TGG GTT TT & 60 \\
PCR & $(133$ bp $)$ & R: TCC AGA TCT GTC TGA TCG TTT C & \\
& $\Delta 7$ SMN2 $(125$ bp $)$ & $\begin{array}{l}\text { F: TGG ACC ACC AAT AAT TCC CC } \\
\text { R: ATG CCA GCA TTT CCA TAT AAT }\end{array}$ & \\
& & AGC C & \\
\hline
\end{tabular}

3. Universal SYBR Green Master Mix.

4. 96-well real-time PCR plate.

5. Sealing film.

6. Real-Time PCR Thermal Cycler.

2.9 Western Blotting 1. Protein extraction buffer: $0.25 \%$ SDS, $75 \mathrm{mM}$ Tris- $\mathrm{HCl}$ (pH 6.8), or RIPA buffer.

2. Protease inhibitor cocktail tablets.

3. Pierce BCA Protein Assay Kit.

4. PBST washing buffer (PBS, pH 7.4, 0.1\% Tween 20).

5. Mini gel tank and blot transfer set.

6. NuPAGE $10 \%$ Bis-Tris precast gels, LDS sample buffer $(4 \times)$, SDS running buffer $(20 \times)$, antioxidant, sample reducing buffer, transfer buffer $(20 \times)$, methanol.

7. Protein molecular weight ladder.

8. PVDF membrane.

9. Odyssey blocking buffer for PVDF membrane blocking.

10. Antibodies: mouse anti-SMN monoclonal antibody (BD Transduction Laboratories), mouse anti- $\beta$-tubulin monoclonal antibody (Sigma), IRDye $800 \mathrm{CW}$-conjugated goat antimouse secondary antibody (Li-Cor).

11. Odyssey imaging instrument to quantify western blot signals.

\section{Methods}

\subsection{Design of Bifunctional Oligonucleotides}

1. Predict the potential binding motifs of the negative splicing regulator heterogeneous nuclear ribonucleoprotein $\mathrm{Al}$ (hnRNP Al) in the target intron or exon sequences, using Human Splicing Finder online software. 


\subsection{Transfection of SMA Fibroblasts}

2. Other splicing repressors, such as intronic splicing silencers and exonic splicing silencers, may also be identified in the literature. A number of annealing sites in intron 6 , exon 7 , and intron 7 have been reported to augment SMN2 exon 7 splicing by bifunctional AONs (Table 2) (see Note 2).

3. AONs, of 15-20 mer in length, are designed to anneal to the potential binding sites of hnRNP Al or other splicing silencers.

4. The GC content of each AON sequence should be $40-65 \%$, with an ideal content of approximately $60 \%$.

5. Avoid four consecutive "G," strong secondary structure or selfcomplementary sequences, and self-dimers.

6. Chemical modifications, e.g., 2'-O-methyl and locked nucleic acid (LNA), may be applied to the antisense sequence to improve stability and increase binding affinity.

7. Select the tail domain. Examples are listed in Table 2.

8. No chemical modifications are recommended in the tail domain except the cap sequence (Fig. 1) [16] (see Note 3).

1. Seed the cells in a 6 -well plate at a concentration of $2 \times 10^{5}$ cells per well, which gives $80 \%$ confluence on the next day.

2. Cells are cultured in $2 \mathrm{~mL}$ of growth medium for $24 \mathrm{~h}$.

3. $24 \mathrm{~h}$ later, change the growth medium to $1 \mathrm{~mL}$ Opti-MEM and leave the cells in the incubator during the preparation of transfection mixes.

4. Prepare the transfection reagent mixes in sterile $1.5 \mathrm{~mL}$ tubes. For each sample, prepare two mixes: the first mix (Mix A) contains $100 \mu \mathrm{L}$ Opti-MEM and $1 \mu \mathrm{L}$ AON at desired concentration (e.g. $1 \mu \mathrm{L} \mathrm{AON}$ at $100 \mu \mathrm{M}$ to get a $100 \mathrm{nM}$ final concentration). While for the mock control add only $100 \mu \mathrm{L}$ Opti-MEM. The second mix (Mix B) contains $100 \mu \mathrm{L}$ OptiMEM and $5 \mu \mathrm{L}$ Lipofectamine 2000.

5. Mix the AON-containing tube (Mix A) with the lipofectaminecontaining tube (Mix B) at a ratio of $1: 1(100 \mu \mathrm{L}+100 \mu \mathrm{L})$.

6. Incubate the transfection $\operatorname{mix}$ for $20 \mathrm{~min}$ at room temperature (RT).

7. Add $800 \mu \mathrm{L}$ Opti-MEM in the transfection mix to top it up to a final volume of $1 \mathrm{~mL}$.

8. Remove Opti-MEM from the 6 well plate and replace with $1 \mathrm{~mL}$ transfection mix in each well.

9. Incubate the plate for at least $6 \mathrm{~h}$ at $37^{\circ} \mathrm{C}$ with $5 \% \mathrm{CO}_{2}$ (see Note 4). 


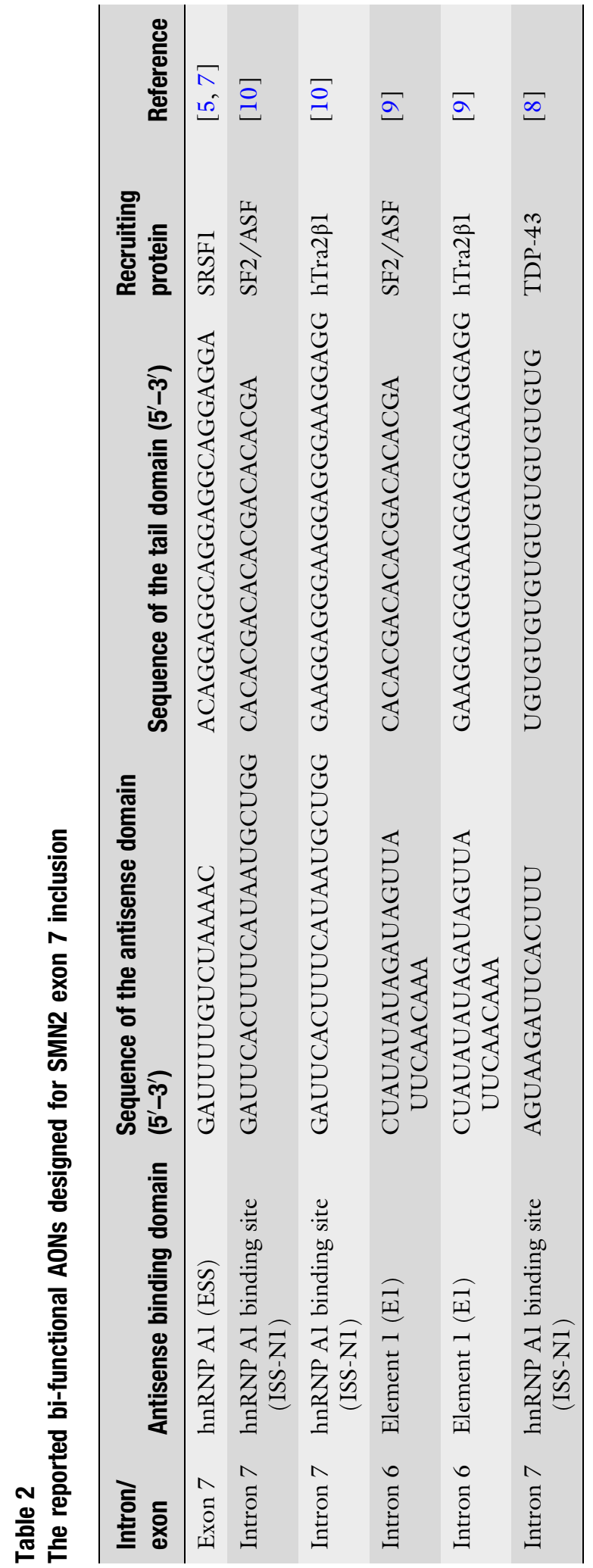




\subsection{Splicing Assay of Bifunctional AONs on SMN2 Exon 7 Inclusion at RNA Level}

1. Extract RNA from SMA fibroblasts using RNeasy Mini Kit according to manufacturer's instruction.

2. Reverse transcription: the cDNA is synthesized from $500 \mathrm{ng}$ RNA using cDNA Synthesis kit according to manufacturer's instruction.

3. PCR of $S M N 2$ transcripts: Use $1 \mu \mathrm{L}$ cDNA in a $25 \mu \mathrm{L}$ PCR reaction with $500 \mathrm{pmol}$ of each primer (Table 1), $200 \mu \mathrm{M}$ of dNTPs, $1.5 \mathrm{mM} \mathrm{MgCl} 2,2.5$ units of Taq polymerase and $1 \times$ PCR buffer. The PCR amplification program is as follows: 1 cycle with $3 \mathrm{~min}$ at $94{ }^{\circ} \mathrm{C}$ (initial denaturation), 25-30 subsequent cycles of $30 \mathrm{~s}$ at $94{ }^{\circ} \mathrm{C}$ (denaturation), $30 \mathrm{~s}$ at $55^{\circ} \mathrm{C}$ (annealing), and $30 \mathrm{~s}$ at $72{ }^{\circ} \mathrm{C}$ (extension), followed by a final 10 -min extension at $72^{\circ} \mathrm{C}$. Check an aliquot of the PCR product $(5-10 \mu \mathrm{L})$ in $1.5 \%$ agarose gel electrophoresis and SYBR safe DNA stain using an UV transilluminator. The top band is the full-length $S M N 2$ product $(505 \mathrm{bp})$. The lower band is the product without exon 7 ( $\triangle 7$ SMN2, $451 \mathrm{bp})$.

4. Quantitative real-time PCR of full-length and $\Delta 7$ SMN2 transcripts: product specific primers (Table 1 ), cDNA and $1 \times$ PCR Master mix are mixed in a $20 \mu \mathrm{L}$ PCR reaction. The program includes activation at $95^{\circ} \mathrm{C}$ for $3 \mathrm{~min}, 40$ cycles of $95^{\circ} \mathrm{C}$ for $10 \mathrm{~s}$, and $60{ }^{\circ} \mathrm{C}$ for $1 \mathrm{~min}$. The cycle at which the amount of fluorescence is above the threshold $(\mathrm{Ct})$ is detected. For quantification, it is possible to use the standard curve method produced from serial dilutions of cDNA from untreated SMA fibroblasts, or the $\Delta \Delta \mathrm{Ct}$ method. Normalize the ratios of full-length $S M N 2$ and $\triangle 7 S M N 2$ to a housekeeping gene (e.g. HPRTI or GAPDH) (see Note 5).

\subsection{Bifunctional AONs on Restoring SMN Protein Measured by Western Blotting}

1. Remove culture medium from the well. Add $100 \mu \mathrm{L}$ ice-cold lysis buffer to the cells. Keep on ice for 5-10 min. Collect lysates using cell scrapers to fresh $1.5 \mathrm{~mL}$ Eppendorf tube and homogenize thoroughly with pipette.

2. Centrifuge at $12,000 \times g$ and $4{ }^{\circ} \mathrm{C}$ for $10 \mathrm{~min}$. Transfer the supernatant to a fresh tube.

3. Measure protein concentration by a NanoDrop spectrophotometer using the Pierce BCA Protein Assay Kit according to the manufacturer's instructions.

4. Load $5 \mathrm{mg}$ total protein into NuPAGE precast gels and then electrophorese.

5. Transfer electrophoretically separated proteins from the gel to a PVDF membrane.

6. Block the PVDF membrane for $1 \mathrm{~h}$ in blocking buffer.

7. Incubate the membrane with the primary antibodies at $4{ }^{\circ} \mathrm{C}$ overnight on a shaker. 
8. Wash the PVDF membrane for $3 \times 10 \mathrm{~min}$ in PBST buffer.

9. Incubate the PVDF membrane with fluorescence secondary antibody for $\mathrm{l} h$ at room temperature.

10. Wash for $3 \times 10 \mathrm{~min}$ in PBST and detect bands using the Odyssey Imaging software (Image Studio).

\section{Notes}

1. DEPC-treated RNase-free water should be avoided to dissolve oligonucleotides. Dissolved AONs should be aliquoted and stored at $-20^{\circ} \mathrm{C}$ and avoid repeated freeze-thaw.

2. For TOES design, the most efficient binding sites of the antisense domain will be the validated exonic or intronic splicing silencers. For exonic silencers, the binding site is favorable to the upstream of the exon.

3. If the antisense domain anneals to an exon, it should avoid inducing any potential exon skipping of the binding exon.

4. Chemical modification of all the RNA nucleotides through the entire tail domain may reduce the binding affinity to protein. However, chemical modification may be only added to the last five nucleotides at the $5^{\prime}$-end of the tail domain (cap, as shown in Fig. 1) to improve the stability while still keep its binding affinity.

5. The duration of transfection can be prolonged to overnight or $24 \mathrm{~h}$. For cells less tolerant to lipofectamine transfection, shorter incubation period, e.g. $6 \mathrm{~h}$, is recommended.

6. It is recommended at least two housekeeping genes are used in the quantitative real-time PCR assay.

\section{Acknowledgments}

This work was supported by the Wellcome Trust, University College London, UK Medical Research Council (MRC), SMA-Europe, SMA Trust, Muscular Dystrophy UK and NIHR Great Ormond Street Hospital and Institute of Child Health Biomedical Research Centre.

\section{References}

1. Dominski Z, Kole R (1993) Antisense oligonucleotides. Proc Natl Acad Sci U S A 90: 8673-8677

2. Mitrpant C, Porensky P, Zhou H, Price L, Muntoni F, Fletcher S et al (2013) Improved antisense oligonucleotide design to suppress aberrant SMN2 gene transcript processing: towards a treatment for spinal muscular atrophy. PLoS One 8:2-11 
3. Hua Y, Sahashi K, Rigo F, Hung G, Horev G, Bennett $F$ et al (2011) Peripheral SMN restoration is essential for long-term rescue of a severe spinal muscular atrophy mouse model. Nature 478:123-126

4. Zhou H, Janghra N, Mitrpant C, Dickinson R, Anthony K, Price L et al (2013) A novel morpholino oligomer targeting ISS-N1 improves rescue of severe spinal muscular atrophy transgenic mice. Hum Gene Ther 24:331-342

5. Singh NK, Singh NN, Androphy EJ, Eliot J, Singh RN (2006) Splicing of a critical exon of human Survival Motor Neuron is regulated by a unique silencer element located in the last intron. Mol Cell Biol 26:1333-1346

6. Mercuri E, Darras BT, Chiriboga CA, Day JW, Campbell C, Connolly AM et al (2018) Nusinersen versus sham control in later-onset spinal muscular atrophy. N Engl J Med 378:625-635

7. Finkel RS, Mercuri E, Darras BT, Connolly NL, Kuntz J, Kirschner CA et al (2017) Nusinersen versus sham control in infantile-onset spinal muscular atrophy. N Engl J Med 377: 1723-1732

8. Hoy SM (2017) Nusinersen: first global approval. Drugs 77:473-479

9. Cirak S, Arechavala-Gomeza V, Guglieri M, Feng L, Torelli S, Anthony K et al (2011) Exon skipping and dystrophin restoration in patients with Duchenne muscular dystrophy after systemic phosphorodiamidate morpholino oligomer treatment: an open-label, phase 2, dose-escalation study. Lancet 378:595-605

10. Kinali M, Arechavala-Gomeza V, Feng L, Cirak S, Hunt D, Adkin C et al (2009) Local restoration of dystrophin expression with the morpholino oligomer AVI-4658 in Duchenne muscular dystrophy: a single-blind, placebocontrolled, dose-escalation, proof-of-concept study. Lancet Neurol 8:918-928

11. Aartsma-Rus A, Corey DR (2020) The 10th oligonucleotide therapy approved: golodirsen for Duchenne muscular dystrophy. Nucl Acids Ther 30:67. https://doi.org/10.1089/nat. 2020.0845
12. Frank DE, Schnell FJ, Akana C, El-Husayni SH, Desjardins CA, Morgan J et al (2020) Increased dystrophin production with golodirsen in patients with Duchenne muscular dystrophy. Neurology 94:e2270. https://doi. org/10.1212/WNL.0000000000009233

13. Heo YA (2020) Golodirsen: first approval. Drugs 80:329-333

14. Skordis LA, Dunckley MG, Yue B, Eperon IC, Muntoni F (2003) Bifunctional antisense oligonucleotides provide a trans-acting splicing enhancer that stimulates SMN2 gene expression in patient fibroblasts. Proc Natl Acad Sci U S A 100:4114-4119

15. Cartegni L, Krainer AR (2003) Correction of disease-associated exon skipping by synthetic exon-specific activators. Nat Struct Biol 10: 120-125

16. Owen N, Zhou H, Malygin AA, Sangha J, Smith LD, Muntoni F et al (2011) Design principles for bifunctional targeted oligonucleotide enhancers of splicing. Nucl Acids Res 39: 7194-7208

17. Brosseau JP, Lucier JF, Lamarche AA, Shkreta L, Gendron D, Lapointe E et al (2014) Redirecting splicing with bifunctional oligonucleotides. Nucl Acids Res 42:e40

18. Baughan TD, Dickson A, Osman EY, Lorson CL (2009) Delivery of bifunctional RNAs that target an intronic repressor and increase SMN levels in an animal model of spinal muscular atrophy. Hum Mol Genet 18:1600-1611

19. Osman EY, Yen PF, Lorson CL (2012) Bifunctional RNAs targeting the intronic splicing silencer $\mathrm{Nl}$ increase SMN levels and reduce disease severity in an animal model of spinal muscular atrophy. Mol Ther 20:119-126

20. Meyer K, Marquis J, Trüb J, Nlend R, Verp S, Ruepp MD et al (2009) Rescue of a severe mouse model for spinal muscular atrophy by U7 snRNA-mediated splicing modulation. Hum Mol Genet 18:546-555

Open Access This chapter is licensed under the terms of the Creative Commons Attribution 4.0 International License (http://creativecommons.org/licenses/by/4.0/), which permits use, sharing, adaptation, distribution and reproduction in any medium or format, as long as you give appropriate credit to the original author(s) and the source, provide a link to the Creative Commons license and indicate if changes were made.

The images or other third party material in this chapter are included in the chapter's Creative Commons license, unless indicated otherwise in a credit line to the material. If material is not included in the chapter's Creative Commons license and your intended use is not permitted by statutory regulation or exceeds the permitted use, you will need to obtain permission directly from the copyright holder.

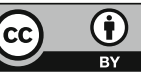

